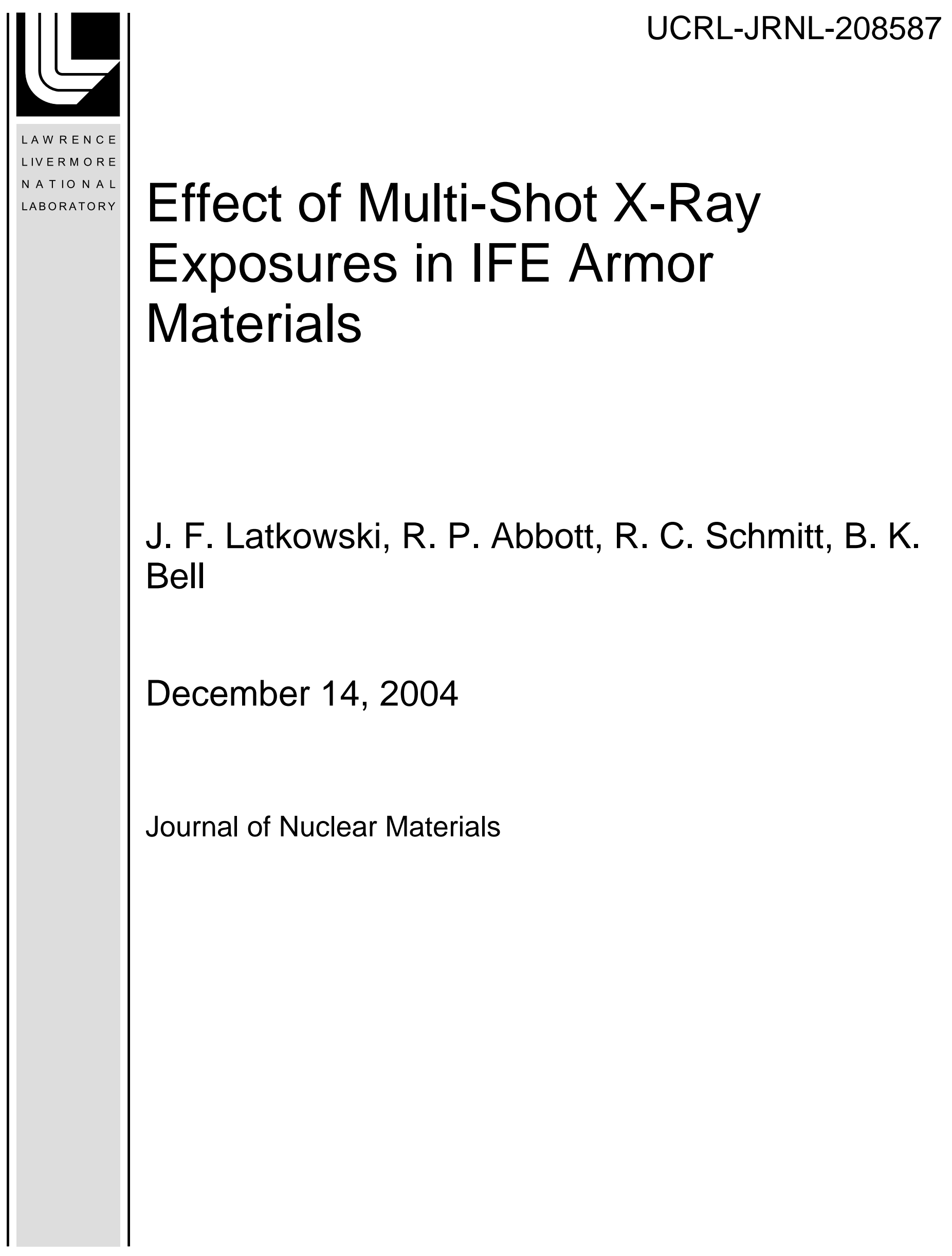


This document was prepared as an account of work sponsored by an agency of the United States Government. Neither the United States Government nor the University of California nor any of their employees, makes any warranty, express or implied, or assumes any legal liability or responsibility for the accuracy, completeness, or usefulness of any information, apparatus, product, or process disclosed, or represents that its use would not infringe privately owned rights. Reference herein to any specific commercial product, process, or service by trade name, trademark, manufacturer, or otherwise, does not necessarily constitute or imply its endorsement, recommendation, or favoring by the United States Government or the University of California. The views and opinions of authors expressed herein do not necessarily state or reflect those of the United States Government or the University of California, and shall not be used for advertising or product endorsement purposes. 


\title{
EFFECT OF MULTI-SHOT X-RAY EXPOSURES IN IFE ARMOR MATERIALS
}

(TO BE SUBMITTED FOR PUBLICATION IN JOURNAL OF NUCLEAR MATERIALS AS PART OF SPECIAL ISSUE ON HAPL CHAMBER WALL)

J. F. Latkowski ${ }^{1}$, R. P. Abbott ${ }^{1,2}$, R. C. Schmitt ${ }^{1,2}$, and B. K. Bell ${ }^{1}$

\author{
${ }^{1}$ Lawrence Livermore National Laboratory, \\ 7000 East Avenue, Mailstop L-641, Livermore, CA 94551 \\ e-mail: latkowski@1lnl.gov
}

${ }^{2}$ University of California at Berkeley, Berkeley, CA 


\begin{abstract}
As part of the High Average Power Laser (HAPL) program the performance of tungsten as an armor material is being studied. While the armor would be exposed to neutrons, x-rays and ions within an inertial fusion energy (IFE) power plant, the thermomechanical effects are believed to dominate. Using a pulsed x-ray source, longterm exposures of tungsten have been completed at fluences that are of interest for the IFE application. Modeling is used in conjunction with experiments on the XAPPER x-ray damage facility in an effort to recreate the effects that would be expected in an operating IFE power plant. X-ray exposures have been completed for a variety of X-ray fluences and number of shots. Analysis of the samples suggests that surface roughening has a threshold that is very close to the fluences that reproduce the peak temperatures expected in an IFE armor material.
\end{abstract}




\section{Introduction}

While it is relatively easy to design components to survive against single-shot damage such as melting, cracking and ablation, this is inadequate when designing an inertial fusion energy (IFE) target chamber. IFE power plants are expected to operate at repetition rates of 5-10 Hz. For a system availability of 85\%, this implies 134-268 million shots per year. At $5 \mathrm{~Hz}$, even $0.1 \mathrm{~nm}$ of material loss per shot would be more than $1 \mathrm{~cm}$ of material removed per year. Clearly, this is not acceptable.

Further, thresholds for single-shot damage are always far greater than those for many shots. For example, Zaghloul, Tillack and Mau [1] have shown that the laser-induced damage fluence for aluminum drops from $\sim 140 \mathrm{~J} / \mathrm{cm}^{2}$ for a single shot to $<20 \mathrm{~J} / \mathrm{cm}^{2}$ for $10^{5}$ shots. Projections give a damage limit of $5-8 \mathrm{~J} / \mathrm{cm}^{2}$ for $10^{8}$ shots. It seems reasonable to assume that a similar decrease in the damage threshold may be observed for $\mathrm{x}$-rays as well. Therefore, it is crucial to conduct experiments at a high repetition rate in order to provide a sufficient number of shots and capture such effects. An experimental repetition rate of $10 \mathrm{~Hz}$ means that exposures of $10^{5}$ shots can be completed on a routine basis, while $10^{6}$ shots is a reasonable upper limit.

Much of the radiation released from an IFE target will be in the form of high-energy neutrons, which will not significantly heat the armor material. The remaining energy is in the form of charged particles and x-rays. Only $\sim 1.4 \%$ of the target output is released as $\mathrm{x}-$ rays, but additional $\mathrm{x}$-rays may be produced via reverse Bremsstrahlung as low-energy ions stop in the chamber gas, if any. The vast majority of the armor heating is caused by charged particles. Output spectra from various IFE target designs have been calculated by L. J. Perkins [2] and can be found at the link given in reference 3. Details of the so-called "threat spectra" and its interaction with the armor in an IFE power plant are given by Raffray et al., in reference 4. In addition, considerable work on this matter has been completed by the team at the University of Wisconsin [5]. Although a wide variety of particle types and energies would be incident upon an IFE first wall, many of the effects are thought to be thermomechanical in nature [6]. As such, an x-ray source is capable of 
serving as an exposure simulator. In the present work, the XAPPER x-ray damage facility is used for this purpose. XAPPER is based upon an extreme ultraviolet (EUV) x-ray source developed and produced by PLEX LLC [7].

\section{Experimental Capabilities}

The XAPPER x-ray damage experiment utilizes an EUV source designed and built by PLEX LLC of Cambridge, Massachusetts [7]. The source operates via a plasma pinch. While the source is capable of operation with argon and nitrogen plasmas, the source output with these gases is significantly lower, and thus, only xenon plasmas have been used to date on XAPPER. Figure 1 shows a typical x-ray spectrum captured using a McPherson grazing incidence spectrometer. The $x$-ray spectrum can be modified by varying the gas pressure within the pinch, the discharge voltage, or by filtering the output prior to striking the sample.

\section{INSERT FIGURE 1 HERE.}

The source output in the EUV is approximately $0.25 \mathrm{~J} / \mathrm{sr}$ with a full-width at halfmaximum (FWHM) pulse length of $\sim 40 \mathrm{~ns}$. For a sample sitting at $30 \mathrm{~cm}$ from the plasma head, this translates into an $\mathrm{x}$-ray fluence of $<0.3 \mathrm{~mJ} / \mathrm{cm}^{2}$. In order to provide a much higher $\mathrm{x}$-ray fluence as well as mitigate debris contamination from the plasma pinch, XAPPER utilizes an ellipsoidal focusing optic. The system layout used in tungsten exposures is indicated in Figure 2. Output from the source is restricted to the range of angles that intercept the focusing optic. This is accomplished using a foil comb, which is shown in Figure 3. The foil comb not only restricts x-ray output to that which intercepts the optic, but it also significantly reduces the amount of debris leaving the plasma head.

INSERT FIGURE 2 HERE. 


\section{INSERT FIGURE 3 HERE.}

To measure the $\mathrm{x}$-ray fluence at the sample plane, a series of measurements is completed prior to each exposure. First, the x-ray power is measured using a vacuum calorimeter from Scientech, Inc. Second, the focused x-ray beam is imaged onto a Princeton Instruments charged coupled device (CCD) camera through a 4- $\square \mathrm{m}$-thick zirconium foil. The zirconium filter reduces the EUV fluence by $\sim 10^{5}$, thereby protecting the CCD camera from severe damage. Figure 4 is an image of a typical $x$-ray spot with a FWHM spot size of $\sim 1 \mathrm{~mm}$. By integrating the background-corrected CCD image, one is able to determine the effective number of counts per unit energy. Given the counts in the peak channel and the size of the pixel, one obtains the peak x-ray fluence. Since the calorimeter is used to determine the power in an unfocused beam, diagnostics are not damaged. Since the CCD measurement is only used to provide an x-ray profile, the measurements are insensitive to the uncertainties in the zirconium filter thickness.

\section{INSERT FIGURE 4 HERE.}

Shot-to-shot variations in the spot location and $\mathrm{x}$-ray fluence are manageable. CCD measurements indicate that the location of the peak intensity has a one-sigma (1- $\square$ ) repeatability of better than 70 microns in an overall spot size of $\sim 1 \mathrm{~mm}$. The peak x-ray fluence has a $1-\square$ repeatability of $11 \%$. Variations in the x-ray fluence are due primarily to source output variability, as indicated by direct photodiode energy measurements.

XAPPER can be operated at repetition rates of up to $10 \mathrm{~Hz}$. Thus, an exposure of $10^{5}$ pulses requires less than 3 hours to complete. To date, the longest exposures completed have been $2 \times 10^{5}$ pulses on aluminum mirrors. Tungsten samples have been exposed for as many as $10^{5}$ pulses. XAPPER can be operated for millions of pulses prior to routine maintenance of the plasma head. 


\section{Modeling}

Computational support is necessary to direct the experimental activities. Modeling of the time-temperature history experienced by an IFE armor is accomplished using the RadHeat finite difference code. RadHeat is able to determine the transient temperature evolution of multi-layer (and material) targets that are exposed to any number of photon and ion spectra. RadHeat allows arbitrary convective cooling (or heating) at the front and back surface, as well as allowing radiation transport with fixed temperature surroundings. RadHeat utilizes an implicit numerical scheme, which leads to increased stability and a faster solution. Additional details regarding RadHeat may be found in Reference 8 .

Using the Perkins target output spectrum for the $154 \mathrm{MJ}$ yield target, heating of the tungsten armor has been calculated. Numerical effects resulting from the ion Bragg peak require one to interpolate between the energy groups provided by Perkins. Typically, each energy bin must be subdivided into as many as twenty separate bins. Both Raffray and Peterson have reported similar effects.

The prompt X-ray pulse is assumed to be a $1 \mathrm{~ns}$ square pulse, while the various ions are all assumed to have a 0.1 ns pulse length. Vacuum conditions are assumed for the 6.5m-radius chamber, and time-of-flight spreading of the ion pulses occurs during transit across the vacuum. Figure 5 shows the surface temperature as a function of time. Note that, due to the logarithmic scale, the intra-pulse details only can be seen for the first of ten pulses. At $\sim 27 \mathrm{~ns}$, a modest spike in the temperature is seen resulting from the prompt $\mathrm{x}$-ray heating. This is followed by the arrival of the burn ions at $\sim 1 \square \mathrm{s}$, and the debris ions at $\sim 1.5 \square$ s. For the first pulse, a peak surface temperature of $3256 \mathrm{~K}$ is calculated. This is similar to results reported by Raffray [4]. Over the first 10 pulses (at $10 \mathrm{~Hz}$ ), the peak temperature ratchets up to $3307 \mathrm{~K}$. This occurs due to the fact that $10 \mathrm{~kW} / \mathrm{m} 2-\mathrm{K}$ is an inadequate heat transfer coefficient for the back surface. The armor has not yet achieved thermal equilibrium in an average power sense. This should occur in the first couple hundred pulses. As shown in Figure 6, calculations using the XAPPER x-ray spectrum 
show that a fluence of $\sim 0.8 \mathrm{~J} / \mathrm{cm}^{2}$ is able to replicate the same peak surface temperature for a sample starting at an initial temperature of $773 \mathrm{~K}$.

\section{INSERT FIGURES 5 and 6 HERE}

Although $0.8 \mathrm{~J} / \mathrm{cm}^{2}$ matches the expected peak surface temperature for the IFE case described above, other fluences are also of interest. Table I lists X-ray fluences used on XAPPER for the exposures presented in this paper. For each fluence, the corresponding peak surface temperature (for the first pulse) is indicated as well. In Table I an initial temperature of $300 \mathrm{~K}$ is assumed (as opposed to $773 \mathrm{~K}$, which is discussed above). XAPPER x-ray exposures have been completed with fluences of $0.5,0.7, \sim 1.0$ and $\sim 1.2$ $\mathrm{J} / \mathrm{cm}^{2}$. The $\sim 1.0$ and $\sim 1.2 \mathrm{~J} / \mathrm{cm}^{2}$ values are approximate, as those particular data sets were taken prior to development of the calorimeter/CCD method for measuring the x-ray fluence. The fluence values are based upon anecdotal evidence, and thus, are suspect to considerably larger error bars.

\section{INSERT TABLE I HERE.}

Temperature-dependent properties for tungsten have been taken from the ARIES web site [9]. Note that a couple of minor changes are made to the basic properties. Specifically, the thermal conductivity has been set to $70 \mathrm{~W} / \mathrm{m}-\mathrm{K}$ for temperatures greater than or equal to $3773 \mathrm{~K}$. Also, the heat capacity has been set to $200 \mathrm{~J} / \mathrm{kg}-\mathrm{K}$ for temperatures greater than or equal to $3273 \mathrm{~K}$ [10]. X-ray opacities for pure tungsten are taken from the Center for X-Ray Optics web site [11]. Figures 7-9 show plots of the data used for these important parameters.

INSERT FIGURES 7-9 HERE

\section{Tungsten Exposures on XAPPER}


Both powder metallurgical (powder met) and single crystal tungsten samples have been exposed to a variety of $\mathrm{x}$-ray fluences and for various numbers of pulses. The $\mathrm{x}$-ray fluences have ranged from 0.5 to $\sim 1.2 \mathrm{~J} / \mathrm{cm}^{2}$, and the number of pulses has ranged from single-shot exposures to as many as $10^{5}$ pulses in a given location. All samples were irradiated beginning at room temperature, but the average x-ray power causes the minimum temperature to "ratchet up" by 200-300 degrees. This is shown in Figure 10.

\section{INSERT FIGURE 10 HERE.}

Tungsten samples have been analyzed using a Veeco white-light interferometer. Preirradiation measurements show an initial surface roughness of $\sim 20 \mathrm{~nm}$ for powder met and $\sim 10 \mathrm{~nm}$ for the single crystal samples. Visual inspection of samples is performed as well. Imaging has been done with a simple digital camera as well as through a low-power microscope. Figure 11 shows images of a single crystal sample that was shot at $0.5 \mathrm{~J} / \mathrm{cm}^{2}$ alongside a powder met sample that was shot with $0.7 \mathrm{~J} / \mathrm{cm}^{2}$. In both cases, a slight discoloration is visible in the location that received $10^{5}$ pulses. Discoloration was also observed in the powder met sample shot at $0.5 \mathrm{~J} / \mathrm{cm}^{2}$ and the single crystal sample shot at $0.7 \mathrm{~J} / \mathrm{cm}^{2}$. In none of these four lower-fluence samples is there obvious damage at the sites that received fewer than $10^{5}$ pulses.

\section{INSERT FIGURE 11 HERE.}

Figure 12 shows a powder met sample that was severely damaged from the $\sim 1.2$ $\mathrm{J} / \mathrm{cm}^{2} \mathrm{x}$-ray fluence. Single-shot damage is evident in this sample. This agrees with our model, which predicts that single-shot melting will occur at $>1 \mathrm{~J} / \mathrm{cm}^{2}$.

\section{INSERT FIGURE 12 HERE.}

Prior to irradiation the single crystal tungsten was quite smooth. Twenty-four measurements from areas throughout the sample, each $240 \times 180 \square \mathrm{m}$ in size, give a surface roughness of $7.7 \pm 1.7 \mathrm{~nm}$. The powder met sample was a bit rougher, with a 
surface roughness of $16 \pm 1.8 \mathrm{~nm}$. When irradiated for as many as $10^{5}$ pulses at $0.5 \mathrm{~J} / \mathrm{cm}^{2}$, neither sample showed any signs of statistically significant roughening. Figures 13a and 13b show a white-light interferometer (WLI) scan of the powder met sample. The scan was taken in the region where visible discoloration of the sample occurred. The powder met surface roughness over about $1 \mathrm{~mm}^{2}$ area increased from 17 to $19 \mathrm{~nm}$ after $10^{5}$ pulses. This is not statistically significant. Similar results are observed for the single crystal sample.

INSERT FIGURE 13a and 13b HERE.

When the x-ray fluence is increased to $0.7 \mathrm{~J} / \mathrm{cm}^{2}$, little or no change occurs in either the single crystal or powder met samples. As Figure 14 shows, the single crystal sample actually may have been smoothed by a small amount. However, the changes do not appear to be statistically significant.

\section{INSERT FIGURE 14 HERE.}

At an x-ray fluence of $\sim 1.0 \mathrm{~J} / \mathrm{cm}^{2}$, some surface roughening is observed. Prior to irradiation, the single crystal roughness was $10 \mathrm{~nm}$, while the powder met was $20 \mathrm{~nm}$. Figure 15 shows pre- and post-irradiation WLI images for the powder met tungsten. After $10^{4}$ pulses, the roughness increased to $72 \mathrm{~nm}$. Interestingly, the single crystal reaches the same roughness after 30,000 pulses at the same fluence. Figure 16 summarizes the $\sim 1.0$ $\mathrm{J} / \mathrm{cm}^{2}$ irradiations. Note that the single crystal roughening appears to be retarded in that it does not begin until sometime between $10^{4}$ and $3 \times 10^{4}$ pulses. This suggests that there may be a threshold below which roughening occurs. It is unclear what effect might cause such behavior. It would be interesting to continue the powder met tungsten exposures beyond $10^{4}$ pulses, as well as taking single crystal tungsten beyond $3 \times 10^{4}$ pulses. It would be interesting to learn whether or not the roughening is linear between numbers of pulses (e.g., between $10^{4}$ and $3 \times 10^{4}$ pulses). Also, it would be interesting to learn whether or not the roughness continues to increase out to a larger number of pulses. 
INSERT FIGURES 15 \& 16 HERE.

For the samples irradiated at a fluence of $\sim 1.2 \mathrm{~J} / \mathrm{cm}^{2}$, a very different result was observed. As Figure 12 shows, severe damage was observed in powder met tungsten, with similar results in the single crystal sample. Given how bad the powder met sample looks to the eye, one might expect that the roughening was catastrophic. This is, in fact, the case. As shown in Table I, tungsten should melt at $\sim 33 \mathrm{~ns}$ into a 40 -ns-long $1.2 \mathrm{~J} / \mathrm{cm}^{2}$ x-ray pulse. This is consistent with the single-shot damage observed in Figure 12.

Given the severity of the visible damage, it is not surprising to learn that the surface has been roughened significantly. Prior to irradiation, this powder met tungsten sample had a surface roughness of $33 \mathrm{~nm}$. With only a single shot at $\sim 1.2 \mathrm{~J} / \mathrm{cm}^{2}$, the roughness increased to $290 \mathrm{~nm}$. Figure 17 shows the WLI measurement results for the spot that received 3000 pulses. Note that the sample is extremely cratered and that portions of the data are missing due to the interferometer's inability to measure at such steep angles within the crater. Clearly, this sample indicates that tungsten could not survive for any reasonable length of time at such high x-ray fluences. This would appear to refute hopes by some that it might be acceptable to allow the surface to melt and re-solidify each pulse.

\section{INSERT FIGURE 17 HERE.}

While the $\sim 1.2 \mathrm{~J} / \mathrm{cm}^{2}$ results are disappointing, they certainly are not surprising. Calculations predict single-shot melting at this fluence, and it far exceeds the expected operating point within an IFE power plant. This is not a disturbing result and in no way causes alarm regarding the design of the tungsten armor for IFE.

\section{Conclusions and Future Work}


The series of experiments reported herein provide bounding circumstances regarding the roughening of various tungsten samples. At x-ray fluences of 0.5 and $0.7 \mathrm{~J} / \mathrm{cm}^{2}$, no statistically significant surface roughening is observed for either powder met or single crystal tungsten. In fact, it is possible that the single crystal tungsten was somewhat smoothed at a fluence of $0.7 \mathrm{~J} / \mathrm{cm}^{2}$. At a fluence of $\sim 1.0 \mathrm{~J} / \mathrm{cm}^{2}$, surface roughening is measurable in both types of tungsten. While the powder met tungsten starts out twice as rough as the single crystal material, the latter roughens significantly after 30,000 pulses. It is noteworthy that the single crystal material does not appear to roughen until a certain number of pulses are exceeded (somewhere between $10^{4}$ and $3 \times 10^{4}$ pulses). At a high fluence of $\sim 1.2 \mathrm{~J} / \mathrm{cm}^{2}$, catastrophic damage is done to both types of tungsten. This is not a surprise as calculations predict that the melt temperature would be reached in a single pulse. This condition significantly exceeds that which is expected in an IFE power plant.

XAPPER will be equipped with a fast, non-contact optical thermometer, which has been developed and built at the University of California at San Diego [12]. This instrument will be installed in December 2004, and it will provide a $\sim 1 \mathrm{~ns}$ resolution in surface temperature measurements. The thermometer will provide a much desired confirmation of fluence measurements and modeling predictions.

Additional work is being done to more accurately measure and predict peak x-ray fluences. A three-axis motor-driven manipulation system for the ellipsoidal condensing optic has been installed. Testing regarding repeatability of optic positioning and fluence measurements is underway.

Considerable additional work is needed. Since a XAPPER fluence of $0.8 \mathrm{~J} / \mathrm{cm}^{2}$ would replicate the expected peak surface temperature for the IFE armor, exposures at this fluence are desired. Long-term ( $>10^{5}$ pulses) exposures at fluences of $0.7 \mathrm{~J} / \mathrm{cm}^{2}$ should be completed to determine if the tungsten will eventually roughen at this marginally lower fluence. Additional exposures at $1.0 \mathrm{~J} / \mathrm{cm}^{2}$ are needed both to replicate the original exposures (recall that the $1.0 \mathrm{~J} / \mathrm{cm}^{2}$ was an approximate value based partially on anecdotal evidence) and to learn if the roughening continues with an increasing number 
of pulses. It is unclear if roughening, unless severe, poses a significant risk to an IFE armor. If the roughening observed at $\sim 1.0 \mathrm{~J} / \mathrm{cm}^{2}$ were to continue in a linear fashion, the surface roughness would be nearly $1 \mathrm{~mm}$ after 1 year of operation at $10 \mathrm{~Hz}$. Would this be a problem? Of course, the roughening could continue to grow linearly until some point at which a critical crack size was exceeded and then a large chunk could break off of the armor. These questions only can be answered with addition x-ray exposures.

Coordination of our activities with those of the other HAPL experiments is needed. Specifically, it is desirable to have each facility run a series of experiments that are as closely matched as possible. This coordination effort is underway and future irradiations will be conducted starting at the same temperature and rising to the same peak surface temperature for each experiment. Later investigations will include matching of the peak stresses as well.

Additionally, swapping of exposed samples between the experiments will be conducted in the future. For example, it would be interesting to see if a previously x-ray irradiated powder met tungsten responds in the same manner to ion implantation as does a virgin sample.

Ultimately, it may be of interest to operate XAPPER with different gases. Argon produces an x-ray spectrum ranging from $250-300 \mathrm{eV}$, while nitrogen yields $400-500 \mathrm{eV}$ photons. These higher-energy photons would be more penetrating, and thus, would more accurately mimic the expected IFE armor conditions. Finally, operating XAPPER at a higher repetition rate also might be of interest. With an inter-pulse dwell time of as little as $100 \square \mathrm{s}$, the thermal transient fully dissipates between pulses. This easily supports a repetition rate of $1 \mathrm{kHz}$, which would enable completion of $10^{8}$ pulses in a 28 hour run. Exposing candidate armor materials to their expected lifetime of pulses might be a very interesting endeavor. Discussions with the x-ray source developer, PLEX LLC, are underway.

This work was performed under the auspices of the U.S. Department of Energy by University of California, Lawrence Livermore National Laboratory under contract W-7405-Eng-48. 


\section{References}

1. M. R. Zaghloul, M. S. Tillack, and T. K. Mau, "Laser-Induced Damage of Metal Mirrors Under Long-Term Exposure at Shallow Angle of Incidence," 19th SOFE, Atlantic City, NJ, Jan. 21-25, 2002.

2. L. J. Perkins, personal communication (2003).

3. Target spectra for reference targets can be found at http://aries.ucsd.edu/ARIES/WDOCS/ARIES-IFE/SPECTRA

4. A. R. Raffray, "Chamber Threats, Design Limits and Design Windows," this issue.

5. R. R. Peterson, D. A. Haynes, I. E. Golovkin and G. A. Moses, "Inertial fusion energy target output and chamber response: Calculations and experiments," Physics of Plasmas, vol.9, no.5, May 2002, pp. 2287-92.

6. J. Blanchard and C. Martin, "Thermomechanical Effects in a Laser IFE First Wall," this issue.

7. M. McGeoch, "Radio-Frequency-Preionized Xenon Z-Pinch Source for Extreme Ultraviolet Lithography,” Appl. Optics 37, 1651 (1998).

8. J. F. Latkowski, R. P. Abbott, and R. C. Schmitt, "Pulsed X-Ray Exposures and Modeling for Tungsten as an IFE First Wall Material," to appear in Fusion Sci. \& Technol.

9. Temperature-dependent properties can be found at: http://wwwferp.ucsd.edu/LIB/PROPS/

10. A. R. Raffray, personal communication (November 2004).

11. X-ray opacity data has been taken from the Center for X-Ray Optics at: http://www.cxro.lbl.gov/optical_constants/filter2.html 
12. Need reference for UCSD thermometer!! 


\section{Tables}

Table I. X-ray fluences used on XAPPER and the corresponding peak surface temperatures for tungsten armor at an initial temperature of $300 \mathrm{~K}$.

\begin{tabular}{|l|l|}
\hline X-ray fluence $\left(\mathrm{J} / \mathrm{cm}^{2}\right)$ & Peak surface temperature $(\mathrm{K})$ \\
\hline 0.5 & 1840 \\
\hline 0.7 & 2470 \\
\hline 0.8 & $2780\left(3250 \mathrm{~K}\right.$ for $\left.\mathrm{T}_{0}=773 \mathrm{~K}\right)$ \\
\hline 1.0 & 3385 \\
\hline 1.2 & Melts $(>3695 \mathrm{~K}) @ 33$ ns into 40 ns pulse \\
\hline
\end{tabular}




\section{List of Figures}

Figure 1. The XAPPER x-ray spectrum ranges from $\sim 80$ to $140 \mathrm{eV}$.

Figure 2. XAPPER experiments utilize an ellipsoidal focusing optic to obtain increased $\mathrm{X}$-ray fluences.

Figure 3. The foil comb reduces debris and restricts $\mathrm{x}$-ray output to those angles that intercept the focusing optic.

Figure 4 . The focused $\mathrm{x}$-ray beam has a spot size of $\sim 1 \mathrm{~mm}$.

Figure 5. RadHeat results for heating of the tungsten armor show a peak surface temperature of $3256 \mathrm{~K}$ for the first pulse and $3307 \mathrm{~K}$ for the tenth pulse.

Figure 6. XAPPER can match the expected armor surface temperature with an x-ray fluence of $\sim 0.8 \mathrm{~J} / \mathrm{cm}^{2}$.

Figure 7 . The tungsten thermal conductivity varies as a function of temperature.

Figure 8 . The tungsten heat capacity varies with temperature. Note that values above $3273 \mathrm{~K}$ have been set to $200 \mathrm{~J} / \mathrm{kg}-\mathrm{K}$.

Figure 9. The x-ray opacity varies as a function of the photon energy.

Figure 10. When XAPPER is operated at $10 \mathrm{~Hz}$, the average X-ray power causes the minimum temperature to increase from $300 \mathrm{~K}$ to as much as $550 \mathrm{~K}$.

Figure 11. In the samples shot at $\mathrm{x}$-ray fluences of 0.5 and $0.7 \mathrm{~J} / \mathrm{cm}^{2}$, subtle damage is visible at the location that received $10^{5}$ pulses. 
Figure 12. Severe damage is observed in this powder met tungsten sample that was shot with an $\mathrm{x}$-ray fluence of $\sim 1.2 \mathrm{~J} / \mathrm{cm}^{2}$.

Figure 13. The surface roughness of powder met tungsten exposed to $10^{5}$ pulses at 0.5 $\mathrm{J} / \mathrm{cm}^{2}$ is essentially unchanged.

Figure 14. Single crystal tungsten may experience some smoothing when exposed to $10^{5}$ pulses at $0.7 \mathrm{~J} / \mathrm{cm}^{2}$.

Figure 15. Powder met tungsten undergoes roughening when exposed to $10^{4}$ pulses at $\sim 1.0 \mathrm{~J} / \mathrm{cm}^{2}$. Note that the height scales differ in the pre- and post-irradiation WLI images.

Figure 16. Surface roughness in powder met and single crystal tungsten grows with an increasing number of pulses at $\sim 1.0 \mathrm{~J} / \mathrm{cm}^{2}$.

Figure 17. The powder met sample exposed to 3000 pulses at $\sim 1.2 \mathrm{~J} / \mathrm{cm}^{2}$ is damaged so severely that the interferometer is unable to collect data within the crater. 
Figure 1.

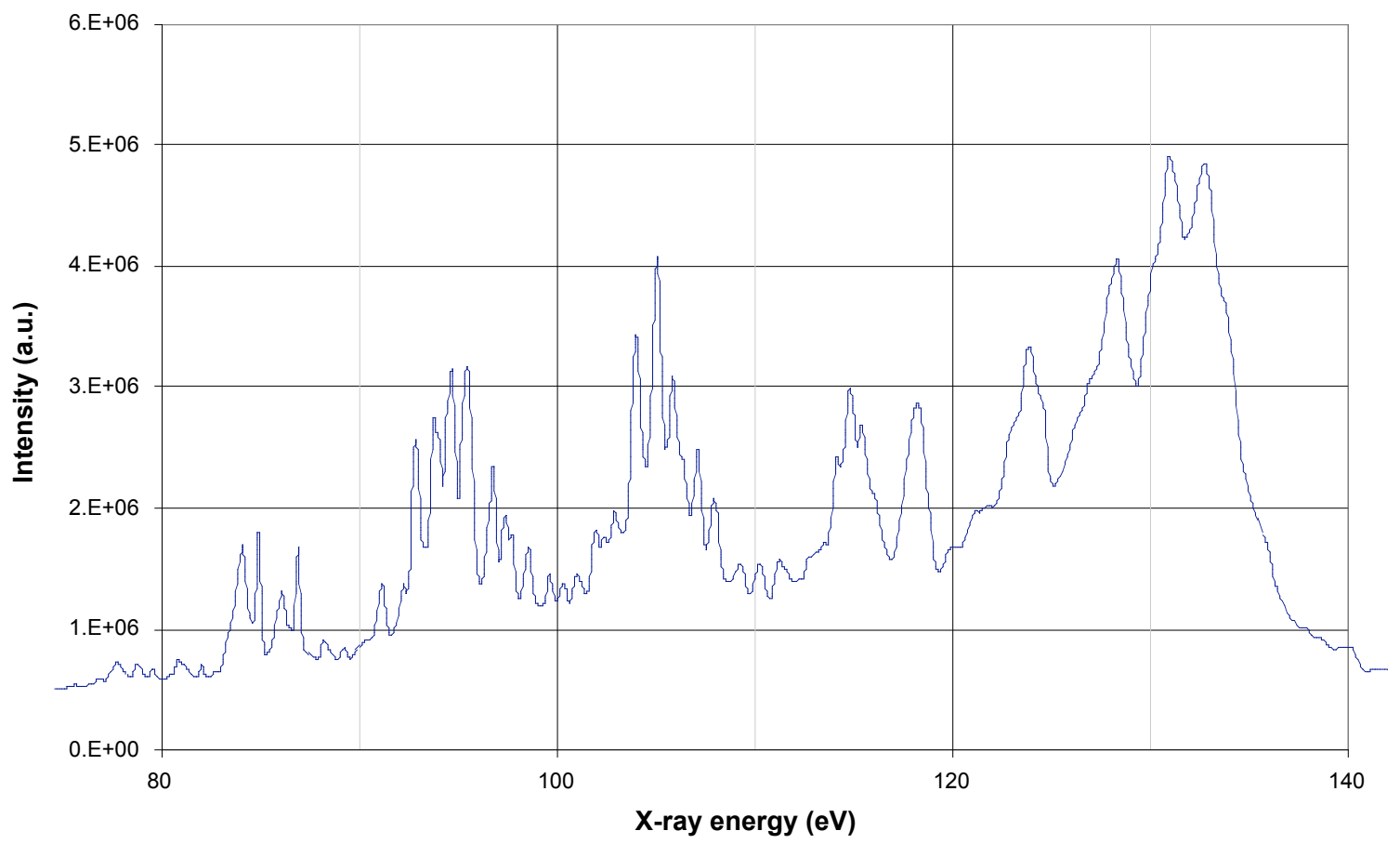

I F I atkowski et al HAPI INM article 
Figure 2.

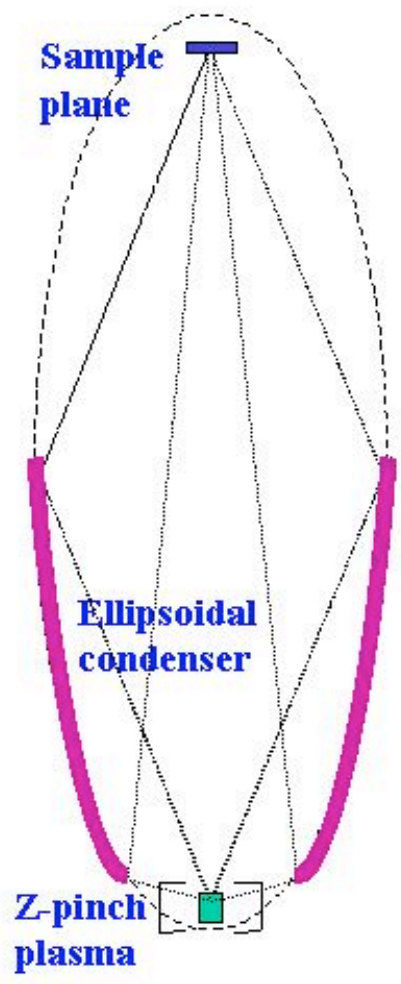

I F I atkowski et al HAPI INM article 
Figure 3.

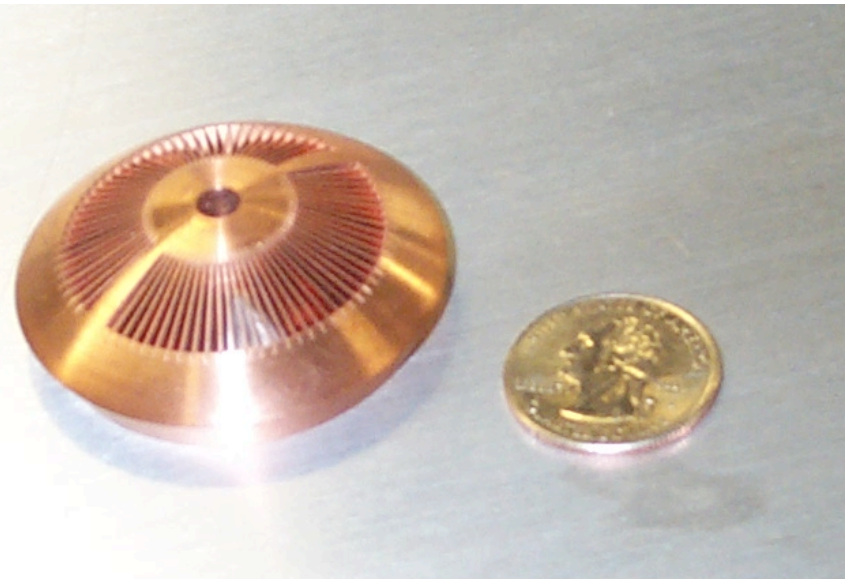


Figure 4.

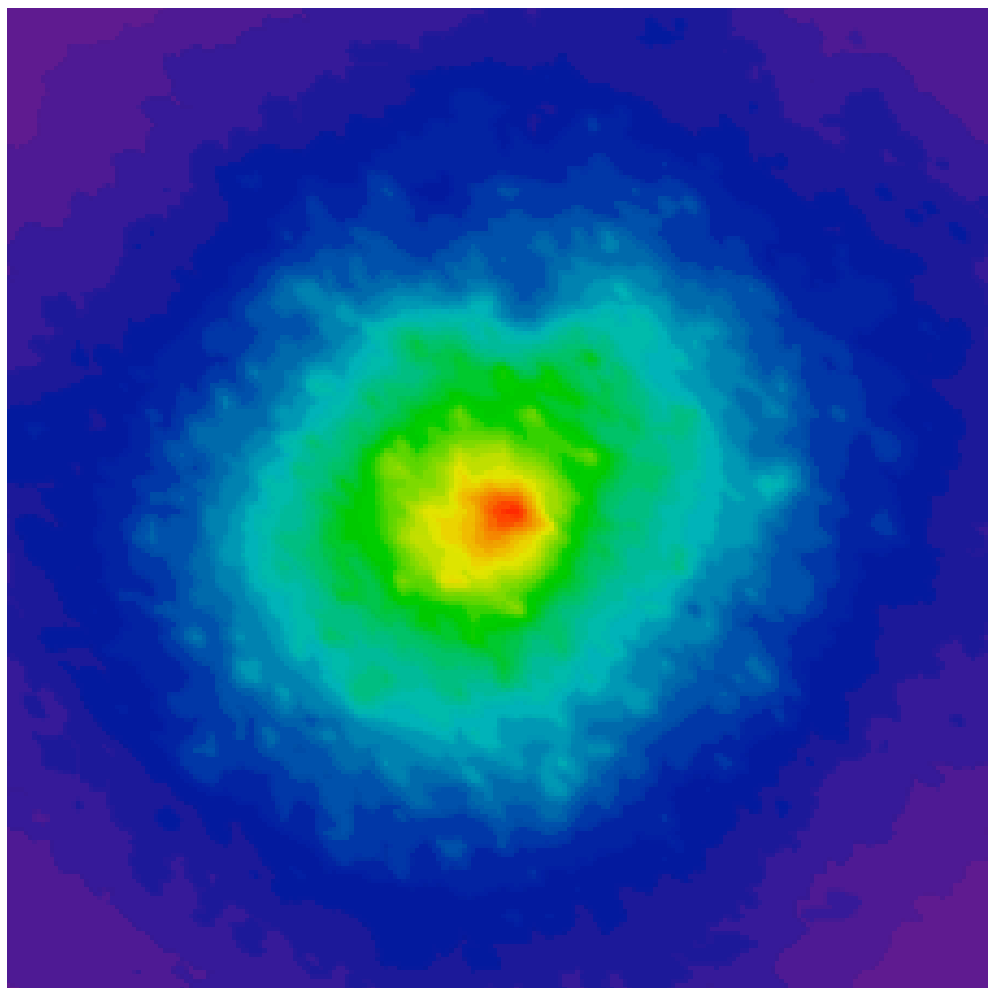


Figure 5.

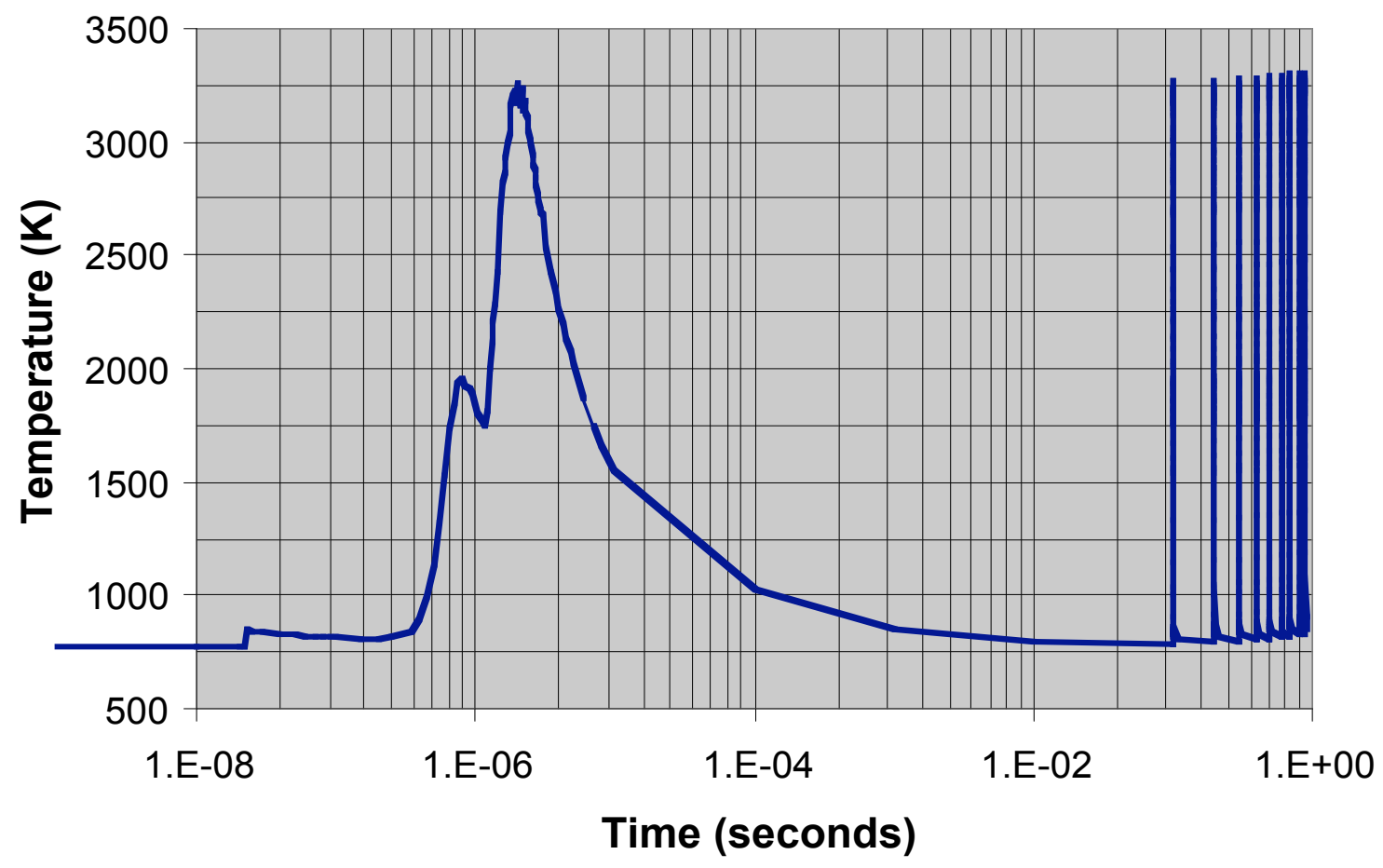

I F I atkowski et al HAPI, INM article 
Figure 6.

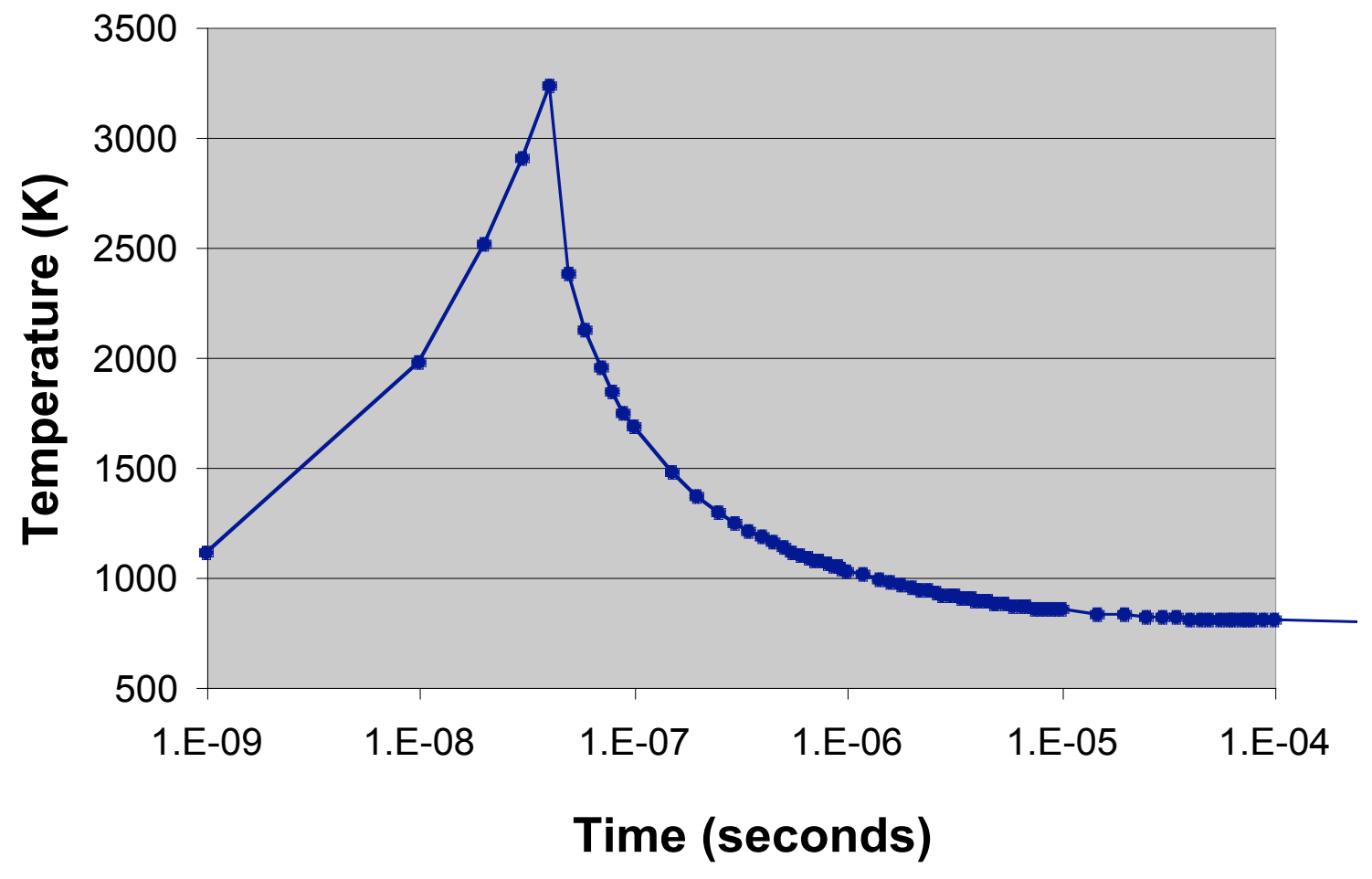


Figure 7.

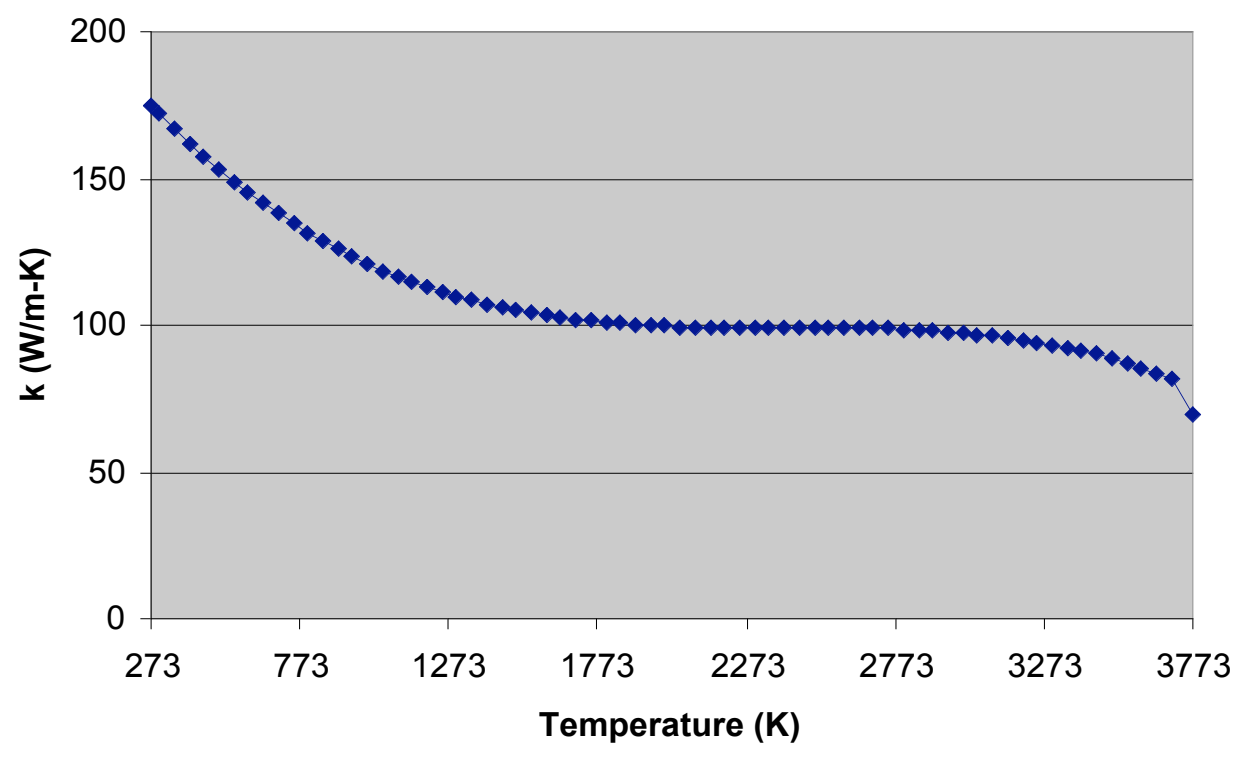

I F I atkowski et al HAPI INM article 
Figure 8.

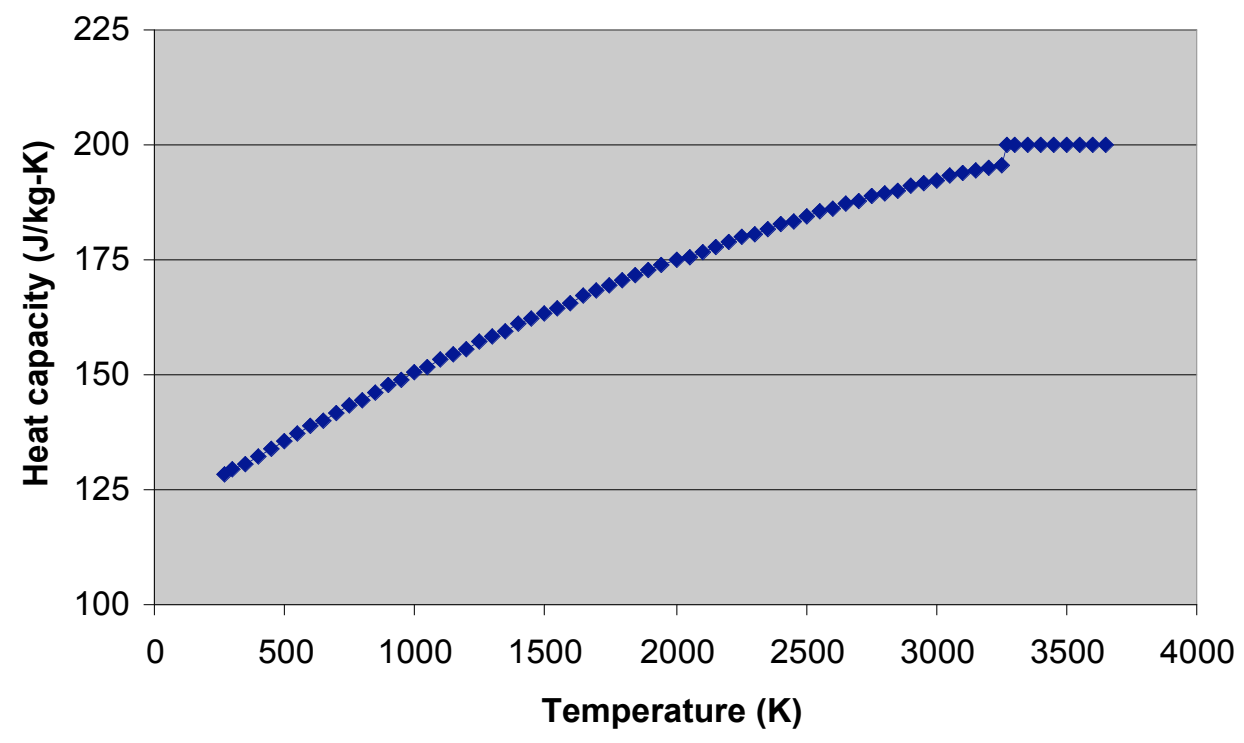

I F I atkowski et al HAPI INM article 
Figure 9.

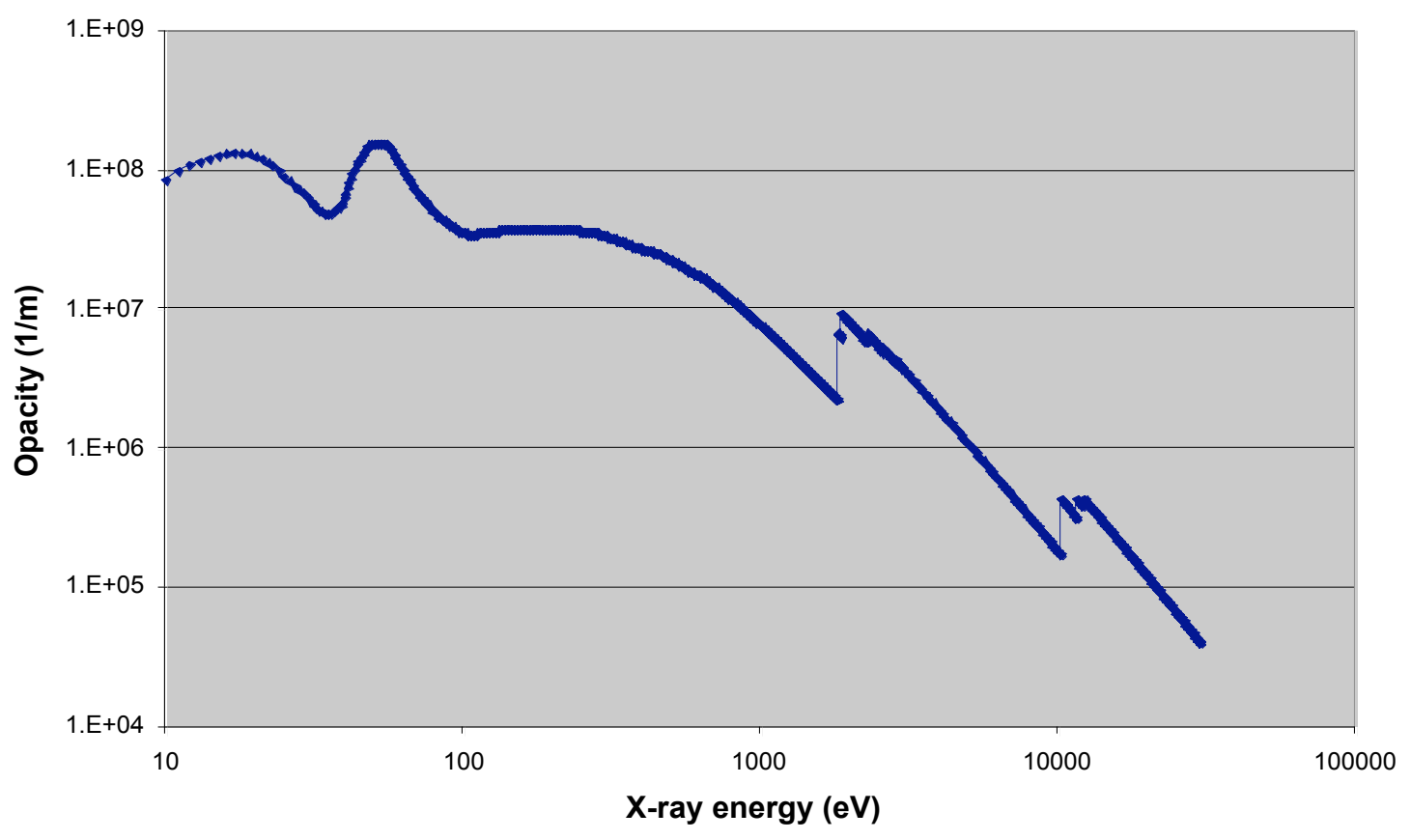


Figure 10.

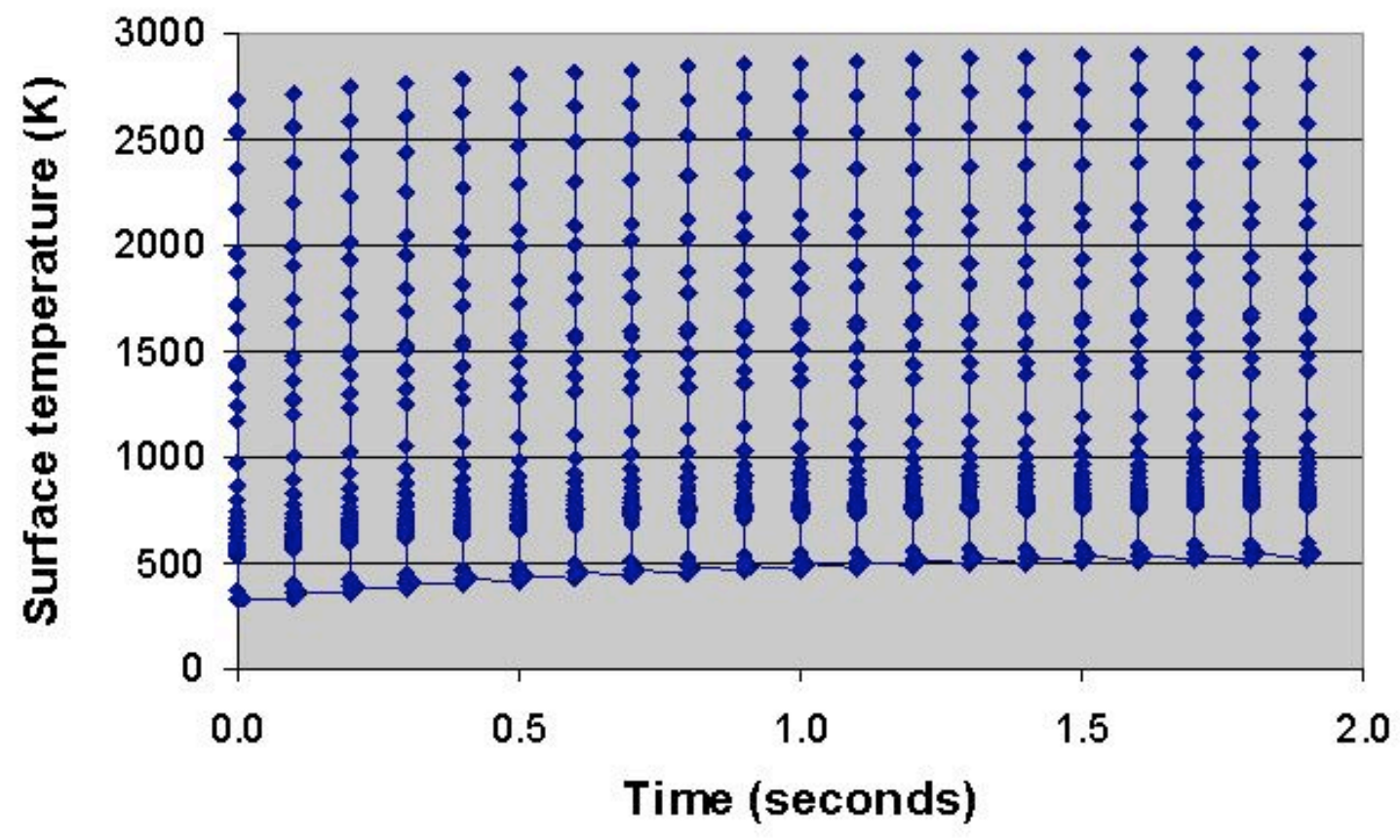

I F I atknwski et al HAPI, INM article 
Figure 11.

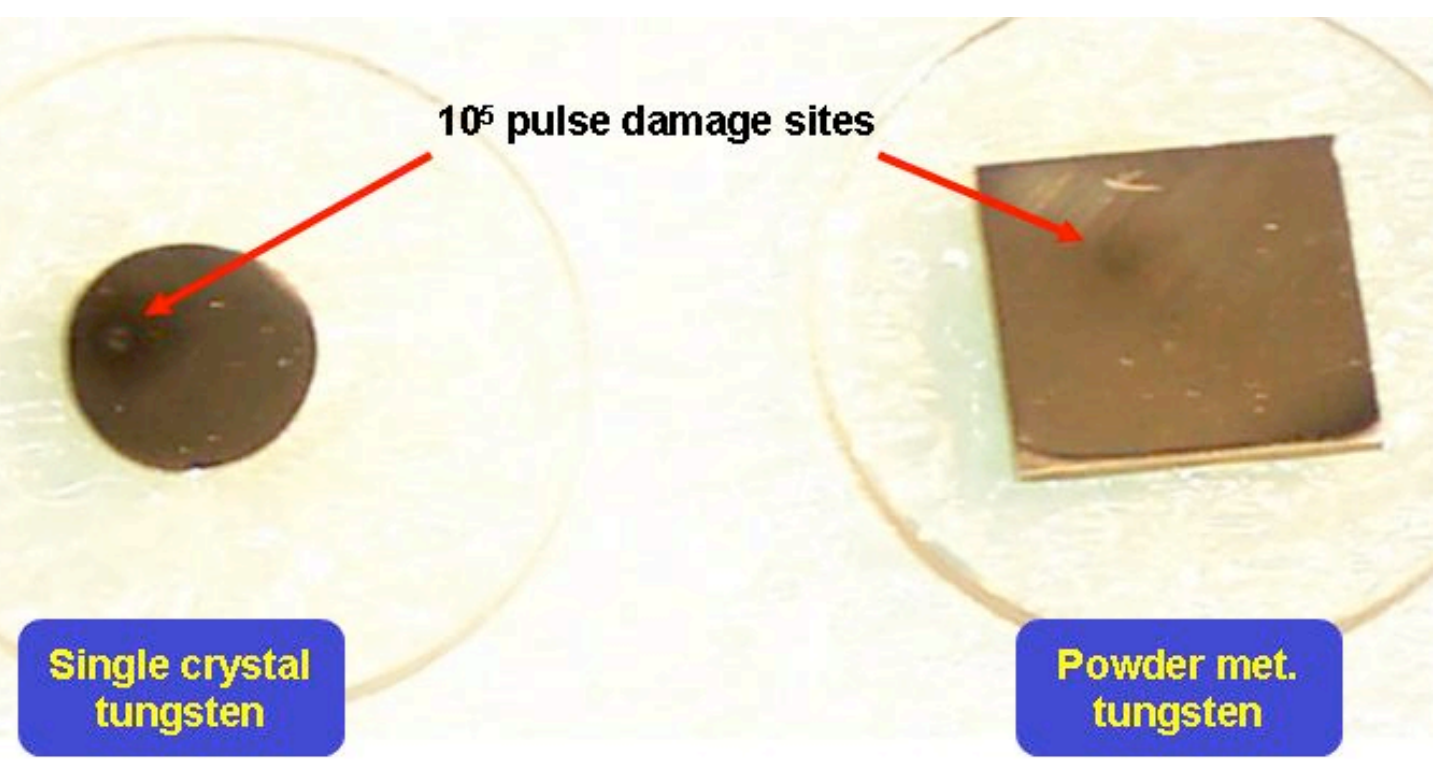


Figure 12.

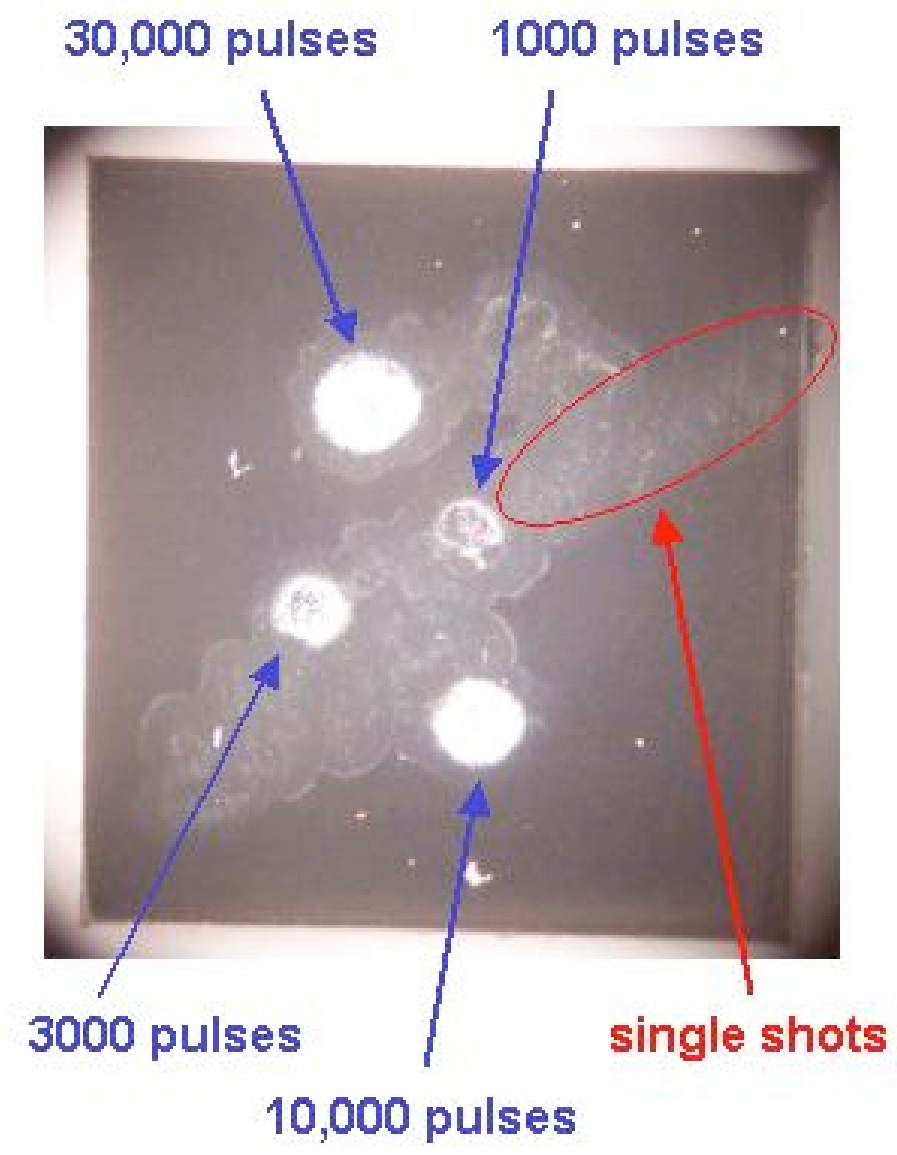


Figure 13.
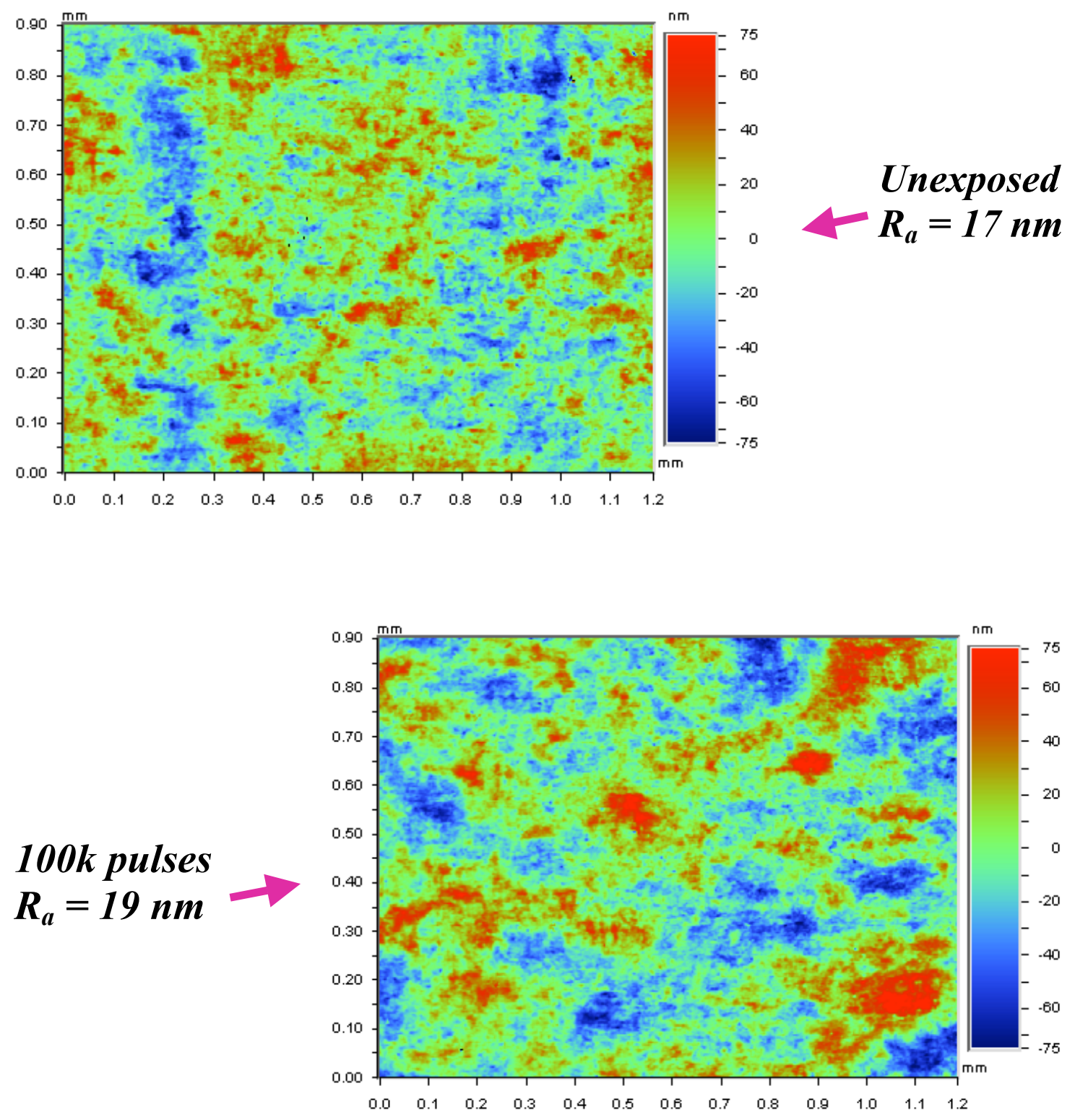
Figure 14.

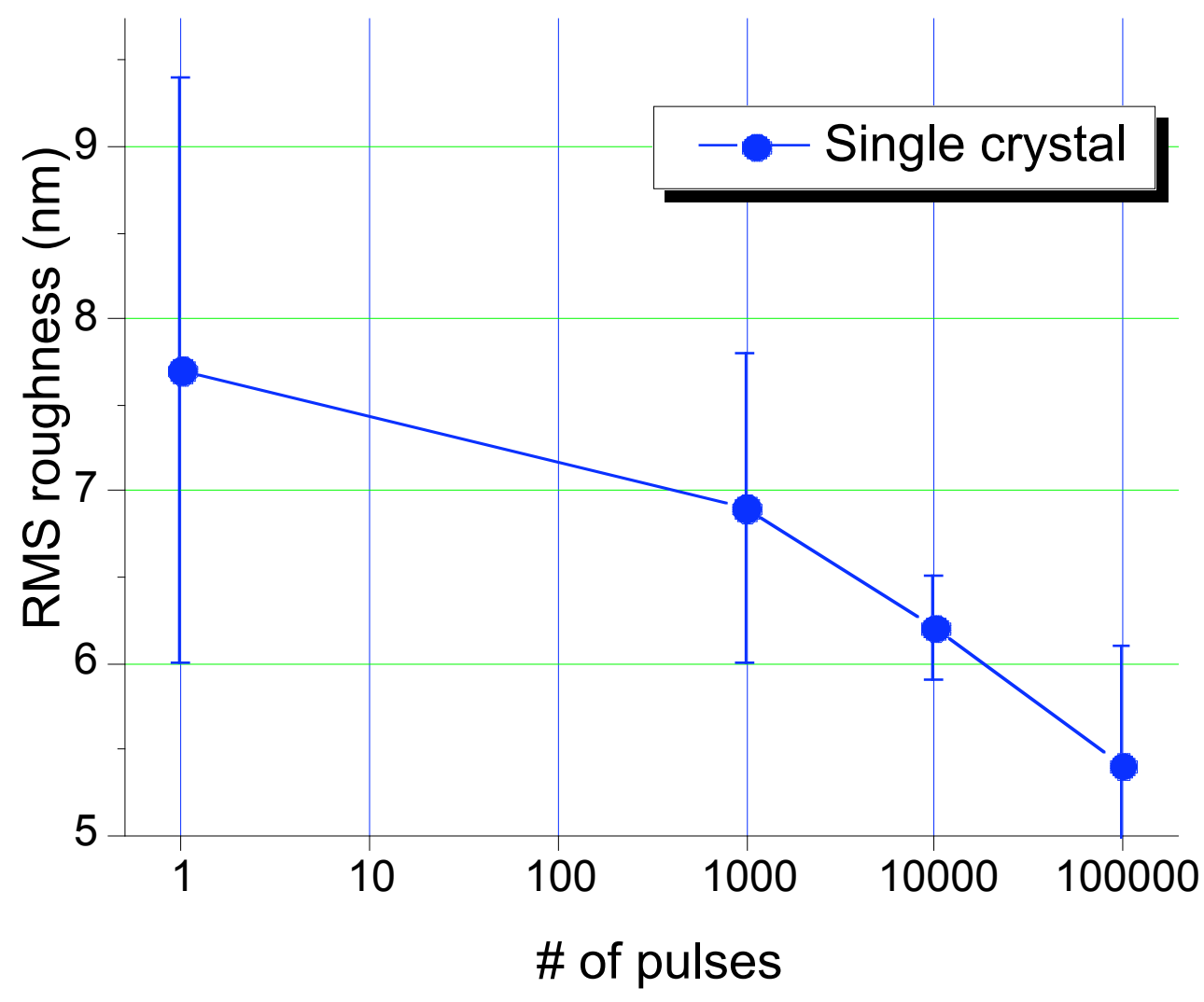

I F I atkowski et al HAPI, INM article 
Figure 15.

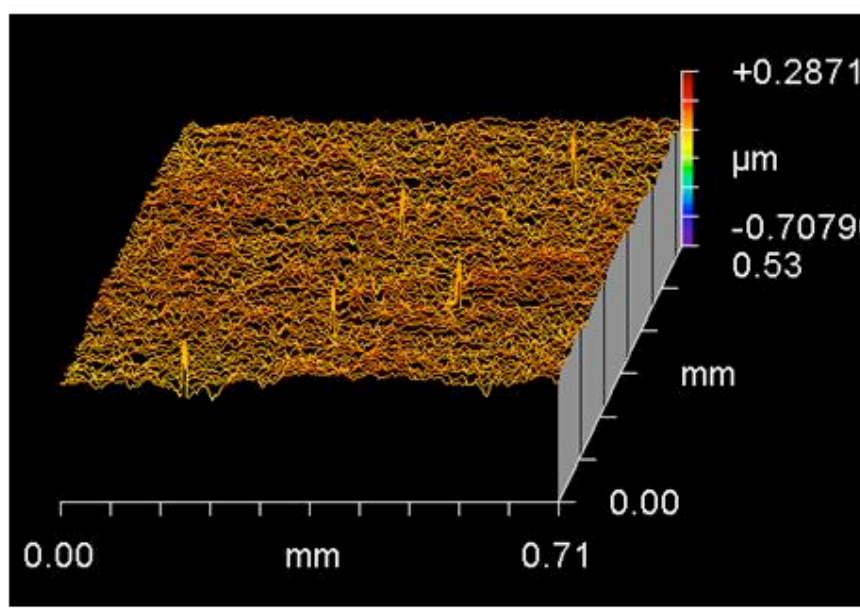

Pre-irradiation:

$m m s=20 n m$

peak-valley $=100 \mathrm{~nm}$

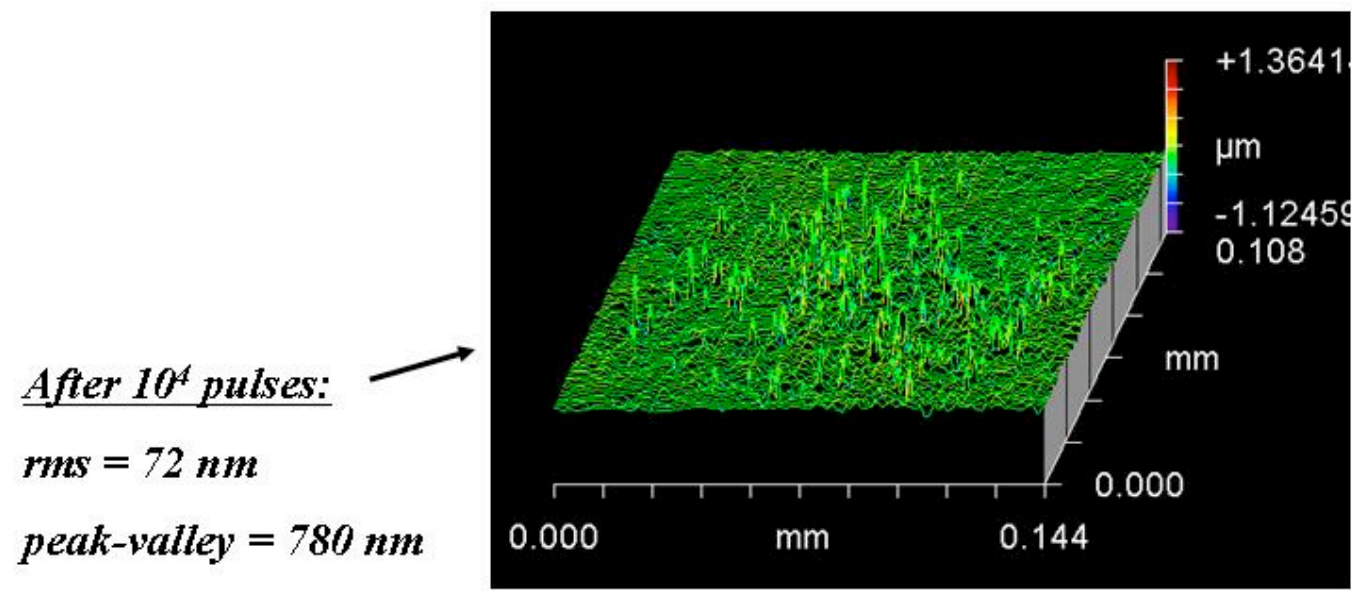


Figure 16.

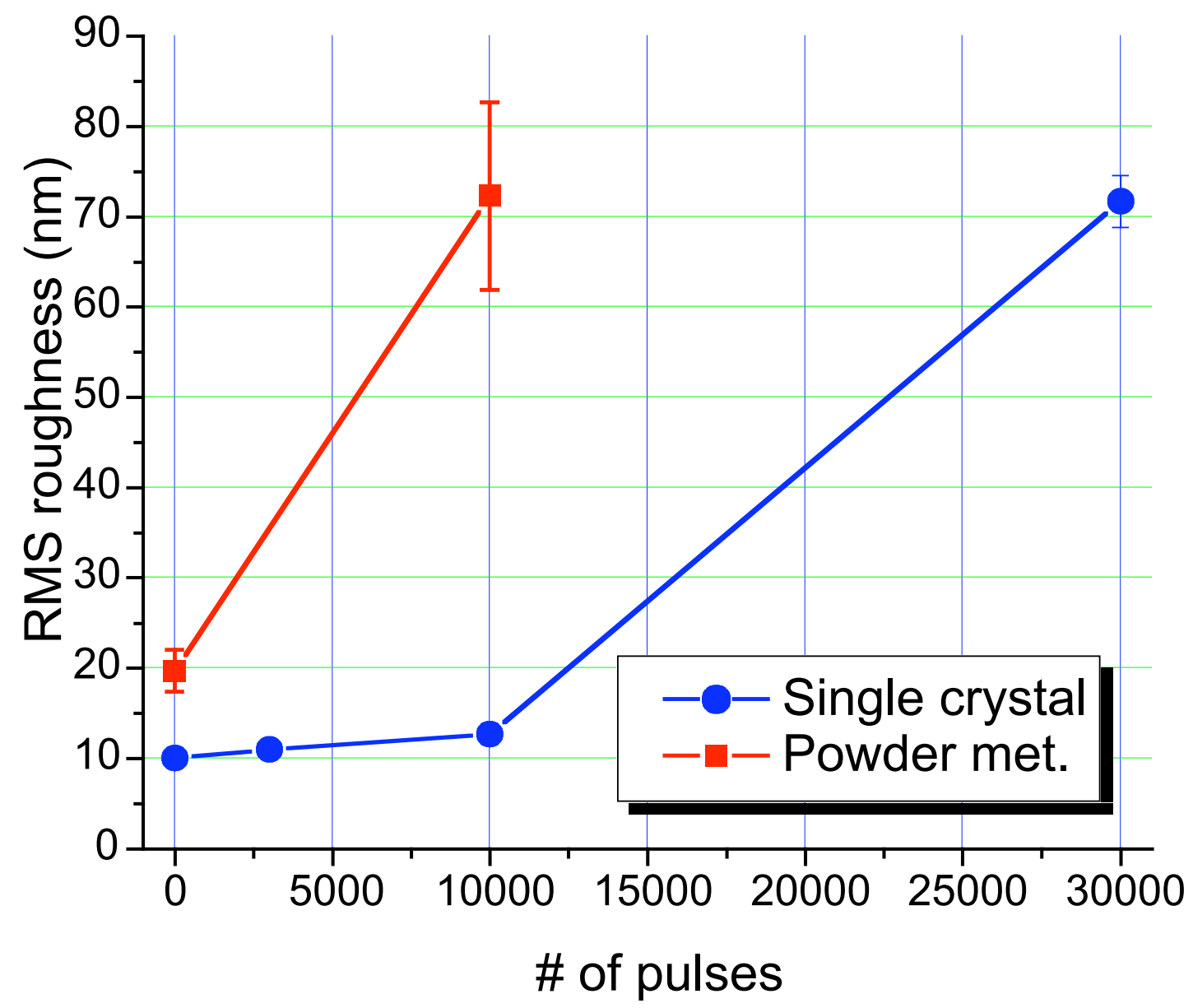

I F I atkowski et al HAPI, INM article 
Figure 17.

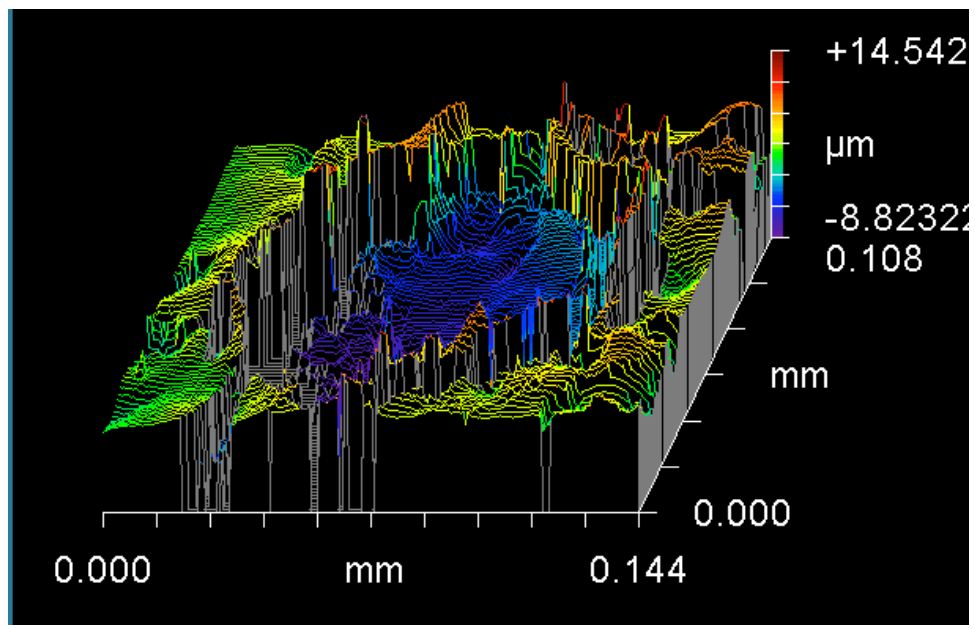

